\title{
FORMULATION AND EVALUATION OF VENLAFAXINE HYDROCHLORIDE SUSTAINED RELEASE MATRIX TABLET
}

\author{
MAHESH PG*, JEGANATH S \\ Department of Pharmaceutics, School of Pharmaceutical Sciences, Vels Institute of Science Technology and Advanced Studies, Pallavaram, \\ Chennai, India. Email: Pgmahesh83@gmail.com
}

Received: 10 October 2018, Revised and Accepted: 11 December 2018

\section{ABSTRACT}

Aim and Objective: Most conventional oral drug products, such as tablets and capsules, are formulated to release the active drug immediately after oral administration, to obtain rapid and complete systemic drug absorption and onset of accompanying pharmacodynamic effects. The term modified release drug product is used to describe that alter the timing and or the rate of release of the drug substances. The objective of the present study was to formulate and evaluate the sustained release matrix tablet of venlafaxine hydrochloride.

Methods: Venlafaxine hydrochloride is a structurally novel antidepressant for oral administration. It is widely prescribed for the treatment of depression, generalized anxiety disorder, and social anxiety disorder. Venlafaxine hydrochloride is currently available as immediate release tablet and as an extended release capsules under the brand names of Effexor (WYETH AYERST) and Effexor XR (WYETH AYERST). The biological half-life of venlafaxine very short ( $5 \mathrm{~h}$ ) and the dose is to be taken 2-3 times a day and the recommended maximum daily dose is $75-450$ mg/day.

Results: Venlafaxine hydrochloride is an antidepressant and so it is to be taken for quite a long period. Hence, to reduce the dosing frequency, simple, lower cost sustained release tablets of venlafaxine were preferred for the development

Keywords: Venlafaxine hydrochloride, Hydroxypropyl methylcellulose, Matrix tablets

(C) 2018 The Authors. Published by Innovare Academic Sciences Pvt Ltd. This is an open access article under the CC BY license (http://creativecommons. org/licenses/by/4. 0/) DOI: http://dx.doi.org/10.22159/ajpcr.2018.v11s4.31729

\section{INTRODUCTION}

A modified-release dosage form is defined as one for which the drugrelease characteristics of time course [1].

\section{EXPERIMENTAL WORK}

\section{Preformulation studies}

Preformulation testing is the first step in the rational development of dosage form of drugs. It involves the application of biopharmaceutical principles to the physiochemical [2] parameters of a drug with the goal of designing an optimum drug delivery system that is stable, bioavailable and can be mass produced [3].

\section{Analytical evaluation}

1. Ultraviolet (UV) spectroscopic analysis.

2. Infrared (IR) spectroscopic analysis.

\section{PREPARATION OF CALIBRATION CURVE OF VENLAFAXINE} HYDROCHLORIDE

\section{Procedure}

Preparation of primary stock solution

A primary stock solution of venlafaxine hydrochloride was prepared by dissolving $100 \mathrm{mg}$ of pure drug in purified water in $100 \mathrm{ml}$ of volumetric flask and volume made up to $100 \mathrm{ml}$ of with purified water.

\section{Preparation of sample solution}

From the primary stock solution, aliquots ranging from $0.05 \mathrm{ml}$ to $0.5 \mathrm{ml}$ were pipetted out and diluted to $10 \mathrm{ml}$ with purified water to get the concentration of $5 \mu \mathrm{g} / \mathrm{ml}-30 \mu \mathrm{g} / \mathrm{ml}$. The absorbance was measured at $274 \mathrm{~nm}$ using UV-visible spectrophotometer.

\section{IR spectroscopic analysis}

The identification of pure drug and excipients was performed using Fourier-transform (FT-IR) spectroscopy. IR absorption spectra of the pure drug and with different excipients were [4] taken using $\mathrm{KBr}$ pressed pellet method [5]. The pellets were prepared by triturating sample and obtained spectra were compared with the reference UV spectroscopic analysis [4]. [6] Pharmaceutical products designed for oral drug delivery are mainly conventional drug delivery systems [7] Sustained drug action pre determined rate by maintaining a relatively constant [8] The effective drug level in the body with concomitant minimization of undesirable side effects [9] The targetted drug action by busing carriers or chemical derivatives to deliver drug to a particular target cell type [10] Targetted release dosage forms may have either immediate or extended release characteristics [11]

\section{FORMULATION DEVELOPMENT}

The study involves the formulation of venlafaxine sustained release matrix tablet

\section{Procedure}

1. Weigh and dissolve ethyl cellulose $95 \%$ in ethanol to prepare $2 \% \mathrm{w} / \mathrm{w}$ solution.

2. Weigh venlafaxine hydrochloride, hydroxypropyl methylcellulose (HPMC), tale, and magnesium stearate and shift through ASTM\#40.

3. Mix the sifted materials for 5 min in a poly bag

4. Add ethyl cellulose solution to dry mix until getting coherent mass: If required add sufficient ethanol 95\%.

5. Air dries the granules and keeps the granules in vacuum oven for overnight.

6. Sift the dried granules through ASTM\#20.

7. Weigh talc and sift through ASTM\#60. 
Table 1: Composition of venlafaxine hydrochloride sustained release matrix tablet

\begin{tabular}{|c|c|c|c|c|c|c|c|}
\hline \multirow[t]{2}{*}{ S. No. } & \multirow[t]{2}{*}{ Ingredients } & F1 & F2 & F3 & F4 & F5 & F6 \\
\hline & & \multicolumn{6}{|c|}{ mg/tablets } \\
\hline 1 & Venlafaxine hydrochloride & 84.86 & 84.86 & 84.86 & 84.86 & 84.86 & 84.86 \\
\hline 3 & Hypromellose (HPMC K15M) & 300 & - & 200 & 200 & 150 & 150 \\
\hline 4 & Hypromellose (HPMC K100M) & - & 300 & 100 & 100 & 100 & 150 \\
\hline 5 & Ethyl cellulose $2 \% \mathrm{w} / \mathrm{w}$ & - & - & - & 16.66 & 16.66 & 16.66 \\
\hline 6 & Ethanol (95\%) & - & - & - & qs & qs & qs \\
\hline 7 & Talc & 5 & 5 & 5 & 27.62 & 26.67 & 27.99 \\
\hline 8 & Magnesium stearate & 450 & 450 & 450 & & & \\
\hline
\end{tabular}

$84.86 \mathrm{mg}$ of venlafaxine hydrochloride equivalent to venlafaxine $75 \mathrm{mg}$, HPMC: Hydroxypropyl methylcellulose

8. Blend the sifted granules and in a poly bag for $30 \mathrm{~min}$

9. Weigh and sift magnesium stearate through ASTM\#40.

10. Lubricate the blend with sifted magnesium stearate for 2 min.

11. Compress the tablets using $12 \mathrm{~mm}$ flat punches with break line on upper punch.

\section{EVALUATION OF TABLET}

The tablets were evaluated for the following characteristics.

\section{Weight variation}

Weigh and dissolve ethyl cellulose $95 \%$ in ethanol to prepare $2 \% \mathrm{~W} / \mathrm{W}$ solution,Mix the sifted materials for $5 \mathrm{mts}$ in a poly bag and the each Venlafaxine hydrochloride weight $84.86 \mathrm{mg}$ equal to venlafaine $75 \mathrm{mg}$ are shown Table 1.

The test ensures that all the tablets in each batch are of same potency, within reasonable limits. According to the USP weight variation test. The specification of the weight variation limits as per USP is given in the following Table 2 .

According to the USP Weight variation test,20 tablets were weighed individually and collectively. Average weight per tablet was calculated from the collective weight. Then the weights of the individual tablets were compared with the average weight to determine the weight variation.

\section{Drug content}

A total of 10 tablets are triturated using mortar and pestle. A quantity of powder weighed equivalent to $84.86 \mathrm{mg}$ of drug was transferred to $100 \mathrm{ml}$ of standard flask and volume made up to $100 \mathrm{ml}$ with purified water.

\section{Hardness test}

A total of 10 tablets from each batch were used and the hardness was expressed in $\mathrm{kg} / \mathrm{mm}^{2}$.

\section{Friability}

Friability test was performed to assess the effect of friction and shock which may often cause tablets to chip, cap, or break.

\section{RESULTS}

\section{Preformulation studies}

\section{UV spectroscopic analysis}

Standard calibration curve of venlafaxine hydrochloride

The absorbance was measured at $274 \mathrm{mn}$ against purified water as blank. The values are given in Table 3 .

\section{IR spectroscopy study}

FT-IR technique was used for the identification of venlafaxine hydrochloride and the blend of finalized formula (F6). The obtained results are given in Table 4.

The IR Spectral studies of blend were carried out to study the interaction between the drug and super disintegrants used. It showed that IR
Table 2: Specification for weight variation of tablets as per USP

\begin{tabular}{ll}
\hline Average weight of tablet & \% deviation \\
\hline $130 \mathrm{mg}$ or less & \pm 110 \\
$>130 \mathrm{mg}$ but $<324 \mathrm{mg}$ & \pm 7.5 \\
$324 \mathrm{mg}$ or more & \pm 5 \\
\hline
\end{tabular}

Table 3: Standard curve for venlafaxine hydrochloride

\begin{tabular}{lll}
\hline S. No. & Concentration $(\mathbf{p g} / \mathbf{m l})$ & Absorbance \\
\hline 1 & 5 & 0.186 \\
2 & 10 & 0.324 \\
3 & 15 & 0.492 \\
4 & 20 & 0.676 \\
5 & 25 & 0.814 \\
6 & 30 & 0.978 \\
\hline
\end{tabular}

Table 4: IR spectra data for venlafaxine hydrochloride

\begin{tabular}{ll}
\hline Frequency $\mathbf{~ H z}$ & Group assigned \\
\hline 3325 & 0-H stretching vibration \\
2929.13 & C-H stretching \\
3001.96 & C-H aromatic stretching \\
1273.6 & C-N stretching vibration \\
1366 & C-N stretching vibration \\
1582.77 & C=C stretching vibration (aromatic) \\
1612.11 & C=C stretching vibration (aromatic) \\
1512.64 & C=C stretching vibration (aromatic) \\
1079.79 & O-H stretching vibration \\
830.55 & C-H deformation vibration \\
\hline IR: Infrared &
\end{tabular}

Table 5: IR spectra data for blend

\begin{tabular}{ll}
\hline Frequency $\mathbf{H z}$ & Group assigned \\
\hline 2920.18 & C-H stretching \\
1020.18 & C-O-C stretching vibration \\
1250.79 & O-H stretching (secondary alcohol) \\
838.26 & C-H deformation \\
1600 & C=C stretching vibration \\
1500 & C=C stretching vibration \\
\hline
\end{tabular}

IR: Infrared

spectrum of pure drug venlafaixne hydrochloride final lubricated blend of table 5 shown some additional peak due to the presents of excipients. Thus on the basis of FT-IR studies, we can conclude that, the drug is compatible with ecipients. The results are shown in Table 5.

\section{Flow properties of blend}

Six formulations are prepared and the lubricated blend was evaluated for various parameters as follows. 
Table 6: Precompression studies of powder blend

\begin{tabular}{|c|c|c|c|c|c|}
\hline Batch code & Angle of repose & Bulk density $\left(\mathrm{g} / \mathrm{cm}^{3}\right)$ & Tapped density $\left(\mathrm{g} / \mathrm{cm}^{3}\right)$ & Compressibility index (\%) & Hausner ratio \\
\hline F1 & $28^{\circ} 81$ & 0.52 & 0.66 & 21.21 & 1.25 \\
\hline F2 & $29^{\circ} 68$ & 0.56 & 0.68 & 17.64 & 1.21 \\
\hline F3 & $27^{\circ} 92$ & 0.52 & 0.65 & 20 & 1.25 \\
\hline $\mathrm{F} 4$ & $26^{\circ} 56$ & 0.58 & 0.72 & 19.44 & 1.24 \\
\hline F5 & $25^{\circ} 74$ & 0.59 & 0.72 & 18.05 & 1.22 \\
\hline F6 & $26^{\circ} 10$ & 0.60 & 0.72 & 16.66 & 1.2 \\
\hline
\end{tabular}

Table 7: Post compression studies of Venlafaxine hydrochloride matrix tablet

\begin{tabular}{|c|c|c|c|c|c|}
\hline Batch code & Thickness (mm) & Hardness $\left(\mathrm{kg} / \mathrm{cm}^{2}\right)$ & Friability (\%) & Drug content (\%) & Weight variation (mg) \\
\hline F1 & $5.41 \pm 0.01$ & $2.83 \pm 0.41$ & 0.52 & 100.2 & $450 \pm 1.08$ \\
\hline F2 & $5.41 \pm 0.02$ & $3.00 \pm 0.45$ & 0.50 & 101.3 & $450 \pm 1.03$ \\
\hline F3 & $5.40 \pm 0.02$ & $3.17 \pm 0.26$ & 0.45 & 99.87 & $450 \pm 1.29$ \\
\hline F4 & $5.20 \pm 0.02$ & $3.33 \pm 0.26$ & 0.32 & 100.3 & $411 \pm 1.03$ \\
\hline F5 & $5.10 \pm 0.04$ & $3.25 \pm 0.27$ & 0.34 & 99.8 & $361 \pm 084$ \\
\hline F6 & $5.21 \pm 0.02$ & $3.42 \pm 0.20$ & 0.28 & 100.4 & $411 \pm 0.78$ \\
\hline
\end{tabular}

\section{Angle of repose}

The present study was undertaken to formulate Venlafaxine hydrochloride matrix tablet with three polymers namely Lactose mono hydrorate, hypromellose, ethyl cellulose and in combination of three super disintegrants and by dry granulation technique. Before compression of the granules physical characters such as bulk density, tapped density, angle of repose, compressibility index and hausner ratio was determined and tabulated in Table 6.

\section{Bulk density}

The bulk density of various granules is measured using graduated cylinder. The bulk density was found in the range of $0.52-0.60 \mathrm{~g} / \mathrm{cm}$. The results are given in Table 6.

\section{Tapped density}

The tapped density of lubricated blends was determined using measuring cylinder. The tapped density was found in the range of 0.65$0.72 \mathrm{~g} / \mathrm{cm}$. The results are given in Table 6 .

\section{Compressibility index and Hausner ratio}

The compressibility index and Hausner ratio of various lubricated blends were calculated using bulk density and tapped density data.

- The compressibility index was found in the ratio of $16.66-21.21 \%$.

- The present study was undertaken to formulate Venlafaine hydrochloride matrix tablet dispersible tablet with three polymers namely sodium starch glycolate, cros carmellose sodium and in combination of three super disintegrants and by dry granulation technique. Before compression of the granules physical characters such as bulk density, tapped density, angle of repose, compressibility index and hausner ratio was determined and tabulated in Table 6 .

The angle of repose of all batches was found between $20^{\circ}$ and $30^{\circ}$ Wh1C1'l indicates that the blends are having good flow property. The results of compressibility index (16.66-21.21\%) and Hausner ratio (1.2-1.25) indicate that the blends are having fair to good flow property.

\section{EVALUATION OF VENLAFAXINE HYDROCHLORIDE SUSTAINED RELEASE MATRIX TABLETS}

Weight variation

The compressed tablets were evaluated for physical properties and the results are tabulated for Hardness test, Thickness test, Friability test, \% of weight variation test and Estimation of drug content values showed in Table 7.
Table 8: In vitro drug release profile for batch $\mathrm{F} 1$ to $\mathrm{F} 6$

\begin{tabular}{lllllll}
\cline { 1 - 5 } Time (h) & & \multicolumn{6}{l}{ Cumulative \% drug release } \\
\cline { 3 - 6 } F1 & & F2 & F3 & F4 & F5 & F6 \\
\hline 77.84 & 86.1 & 79.4 & 49.44 & 60.72 & 13.62 \\
79.4 & 92.2 & 82.3 & 50.26 & 66.36 & 26.28 \\
83.2 & 94.8 & 90.8 & 51.0 & 69.36 & 38.16 \\
87.6 & 95.3 & 96.9 & 53.16 & 70.44 & 49.72 \\
89.8 & 96.8 & 102.2 & 55.96 & 72.0 & 55.8 \\
92.16 & 97.8 & & 61.08 & 74.52 & 60.05 \\
94.82 & 98.2 & & 63.72 & 77.16 & 62.52 \\
97.6 & 99.82 & & 64.8 & 79.44 & 65.16 \\
98.8 & 101.6 & & 67.44 & 82.08 & 68.16 \\
100.9 & & & 69.72 & 84.36 & 71.52 \\
& & & 74.16 & 87.0 & 75.72 \\
& & & 78.36 & 89.52 & 79.08 \\
\hline
\end{tabular}

Table 9: Release profile of innovator product (EffexorTm-XR)

\begin{tabular}{ll}
\hline Time (h) & Average \% venlafaxine hydrochloride released \\
\hline 2 & $<30$ \\
4 & $30-55$ \\
8 & $55-80$ \\
12 & $65-90$ \\
24 & $<90$ \\
\hline
\end{tabular}

The prepared tablets were evaluated for weight variation. All the tablets are the acceptable range of weight variation as per USP specification, i.e., less than $15 \%$. The results are given in Table 7.

\section{Thickness}

The thickness of the tablets was determined by Vernier caliper and found in the range of 5.40-5.44 $\mathrm{mm}$. The results are given in Table 7.

\section{Hardness}

Hardness of tablets was calculated by Monsanto Hardness tester and found in the range of $2.5-2.7 \mathrm{~kg} / \mathrm{cm}^{2}$. The results are given in Table 7 .

\section{Friability}

Tablets were evaluated using Roche friabilator and friability of tablets was observed in acceptable range of $0.28-0.52 \%(<1 \%)$, which shows that the tablets are mechanical stable and could handle the rigors of transportation and handling. The results are given in Table 7.

\section{Estimation of drug content}

The tablets were evaluated for drug content by assay method. The drug content was found in the range of $99.8-100.4 \%$. The results are given 
Table 10: Kinetic release data for optimized formulation

\begin{tabular}{|c|c|c|c|c|c|}
\hline \multicolumn{2}{|c|}{ Zero-order plot } & \multicolumn{2}{|l|}{ Higuchi plot } & \multicolumn{2}{|c|}{ Korsmeyer and Peppas plot } \\
\hline Time (h) & $\begin{array}{l}\text { Cumulative } \% \\
\text { drug release }\end{array}$ & $\begin{array}{l}\text { Square root } \\
\text { of time }\end{array}$ & $\begin{array}{l}\text { Cumulative } \% \\
\text { drug release }\end{array}$ & $\begin{array}{l}\text { Log } \\
\text { time }\end{array}$ & $\begin{array}{l}\text { Log cumulative \% } \\
\text { drug release }\end{array}$ \\
\hline 2 & 26.28 & 1.41 & 26.28 & 0.30 & 13 \\
\hline 3 & 38.16 & 1.73 & 38.16 & 0.47 & 1.41 \\
\hline 4 & 49.52 & 2.00 & 49.52 & 0.60 & 1.58 \\
\hline 5 & 55.8 & 2.23 & 55.8 & 0.69 & 1.69 \\
\hline 6 & 60.05 & 2.44 & 60.05 & 0.77 & 1.74 \\
\hline 7 & 62.52 & 2.64 & 62.52 & 0.84 & 1.77 \\
\hline 8 & 65.16 & 2.82 & 65.16 & 0.90 & 1.79 \\
\hline 9 & 68.16 & 3.00 & 68.16 & 0.95 & 1.81 \\
\hline 10 & 71.52 & 3.16 & 71.52 & 1.00 & 1.83 \\
\hline 11 & 75.72 & 3.31 & 75.72 & 1.04 & 1.87 \\
\hline 12 & 79.08 & 3.46 & 79.08 & 1.07 & 1.89 \\
\hline
\end{tabular}

in Table 7

\section{IN VITRO DISSOLUTION STUDY}

In vitro drug release study of venlafaxine hydrochloride sustained matrix tablet was carried out in purified water at temperature $37 \pm 0.5^{\prime} \mathrm{c}$ with basket rotation at $100 \mathrm{rpm}$ for $12 \mathrm{hrs}$.

In order to find out the order of release and mechanisms, which was predominantly influence the drug release from the tablets, the in vitro dissolution data was subjected to graphical treatment is percentage cumulative drug release VS time.

In vitro dissolution profile of first three batches (F1, F2, F3) shown burst release. Among the net three batches (F4, F5, F6) F6 shown good control in initial time points( upto $4 \mathrm{th} \mathrm{hr}$ ) and matching with release profile of EFFEOR XR are shown in Table 8.

Release profile of innovator product was mentioned in Time in the ranges of 2,4,8,12,24 vs average of venlafaxine hydrochloride are shown in Table 9.

Here the data was plotted as a graph according to Zero order plot, Higuchi plot, korsmeyer \& peppas plot, cumulative percentage of drug release along Y-axis and square root of time (hrs) along-axis are shown Table 10.

\section{STUDY OF DRUG RELEASE KINETICS}

The data were plotted as graph according to zero-order kinetics, cumulative percentage of drug release along Y-axis and time (h) along X-axis.

The data were plotted as a graph according to Higuchi's plot, cumulative percentage of drug release along Y-axis and square root of time (h) along X-axis. The plot was found to be linear and the linear regression coefficient value is $\mathrm{R} 2=0.963 \mathrm{l}$ so it is obvious that the drug release obeys gel diffusion mechanism.

The data were plotted as a graph according to Peppers plot log cumulative percentage of drug release along Y-axis and log time (hrs) along X-axis.

\section{DISCUSSION}

The main goal of this work to develop sustained release matrix tablets of venlafaxine hydrochloride and to find out the effect of polymers on the various parameters of tablets such as dissolution and drug release.

Venlafaxine hydrochloride is an antidepressant having short biological half-life $(5 \mathrm{~h})$. Hence, to reduce the dosing frequency and the side effects, sustained release matrix tablet was formulated.
Three formulations were prepared by direct compression using different grades of hydroxypropyl methylcellulose polymers such as KI5M and KIOOM. Further, three formulations were taken with ethyl cellulose $(2 \% \mathrm{w} / \mathrm{W})$ dispersion in ethanol (95\%) by wet granulation process.

\section{SUMMARY}

Venlafaxine hydrochloride is a structurally novel antidepressant for oral administration. The drawback of venlafaxine hydrochloride is short half-life. To give dose for long-term therapy with multidose regimen, patient compliance is the difficult to achieve. Hence, to reduce the dosing frequency, simple, lower cost sustained release tablets of venlafaxine hydrochloride were preferred for the development.

Analytical method was developed for venlafaxine hydrochloride using UV spectrometer at Kmax of $274 \mathrm{mn}$. It obeys the Lambert's law between 5 and $30 \mu \mathrm{g} / \mathrm{ml}$. FT-IR study of pure drug, excipients, and blend of final formula was studied and the result confirms that the drug is compatible with other excipients. Three formulations of venlafaxine hydrochloride tablet were prepared by direct compression process, with different ratio of HPMC Kl5M and KIOOM. The dissolution of compressed tablets showed initial burst release.

Hence, three batches were formulated using ethyl cellulose $(2 \% \mathrm{w} / \mathrm{w})$ dispersions in ethanol (95\%) and using HPMC KISM and KIOOM by wet granulation process. The formulated tablets are shown good control initial time points. Among the batches taken, batch F6 shown a controlled release characteristics. All the formulations were evaluated for physical parameters such as weight variation, thickness, hardness, and friability.

The results indicate that all the formulations were within the acceptable limit.

\section{CONCLUSION}

The venlafaxine hydrochloride sustained release matrix tablets shown controlled release profile as per the release profile of the innovator is EffexorTm_XR. The sustained release of this matrix tablet reduces the dosing frequency and reduces the side effects, by which in a long-term therapy, it may be useful as a product with patient compliance for the treatment of major depression disorder.

\section{REFERENCES}

1. Avachat A, Kotwal V. Design and evaluation of matrix-based controlled release tablets of diclofenac sodium and chondroitin sulphate. AAPS PharmSciTech 2007;8:E88.

2. Kuksal A, Tiwary AK, Jain NK, Jain S. Formulation and in vitro, in vivo evaluation of extended-release matrix tablet of zidovudine: Influence 
of combination of hydrophilic and hydrophobic matrix formers. AAPS PharmSciTech 2006;7:E1.

3. Basak SC, Reddy BM, Mani KP. Formulation and release behaviour of sustained release ambroxol hydrochloride HPMC matrix tablet. Indian J Pharm Sci 2006;3:594-7.

4. Bhalla HL, Handa AK. Development and evaluation of controlled release tablets of carbamazepine. Indian Drugs 1999;36:100-5.

5. Bolton S, Bon C. Pharmaceutical Statistics: Practical and Clinical Applications. New York: Marcel Dekker; 2004.

6. Boume DW. Pharmacokinetics. In: Banker GS, Rhodes CT, editors. Modern Pharmaceutics. $4^{\text {th }}$ ed. New York, NY: Marcel Dekker; 2002. p. 67-92.

7. Bramhanker DM, Jaiswal SB. Controlled release medications. In: Biopharmaceutics and Pharmacokinetics a Treatise. New Delhi:
Vallabh Prakashan; 1995. p. 335-375

8. Chien YW. Controlled and modulated-release drug delivery systems. In: Swarbrick J, Balyan JC, editors. Encyclopedia of Pharmaceutical Technology. New York: Marcel Dekker; 1990. p. 281-313.

9. Chien YW. Novel Drug Delivery Systems. $2^{\text {nd }}$ ed. New York: Marcel Dekker, Inc.; 1992.

10. Colombo P, Bettini R, Catellani PL, Santi P, Peppas NA. Drug volume fraction profile in the gel phase and drug release kinetics in hydroxypropylmethyl cellulose matrices containing a soluble drug. Eur J Pharm Sci 1999;9:33-40.

11. Colombo P, Bettini R, Massimo G, Catellani PL, Santi P, Peppas NA, et al. Drug diffusion front movement is important in drug release control from swellable matrix tablets. J Pharm Sci 1995;84:991-7. 